\title{
Environmental and visitor management in a thousand protected areas in China
}

Linsheng Zhong ${ }^{\mathrm{a}}$, Ralf C. Buckley ${ }^{\mathrm{a}, \mathrm{b}, *}$, Cassandra Wardle ${ }^{\mathrm{b}}$, Lingen Wang ${ }^{\mathrm{a}}$

${ }^{a}$ Institute of Geographic Sciences and Natural Resources Research, Chinese Academy of Sciences, Beijing 100101, China

${ }^{\mathrm{b}}$ International Chair in Ecotourism Research, Griffith University, 4222, Australia

\section{Keywords:}

Conservation, Asia, Impacts, Policy, Management, Recreation, Threatened-species

\section{ABSTRACT}

China has $\sim 8000$ protected areas, with different categories and levels of designation. These include many reserves of global conservation significance. There are more numerous but smaller parks in the more heavily populated provinces of the south and east, and fewer larger parks in the northwest. We sampled 1200 representative parks nationwide, using questionnaires delivered to park managers in person, with 160 categorical or ordinal parameters. Response rate was $92.5 \%$. We carried out three analyses: first, for each parameter independently; second, for five multi-parameter aggregate indices; and third, for two toplevel indices of environmental and visitor management respectively. We tested for patterns by category, level, size, age, region, visitor volume and revenue, with $>600$ individual tests, and $>70$ patterns significant at $p<0.0001$. We found that both environmental and visitor management practices are more intensive for large, old, rich, heavily visited parks. A number of parks receive $>100,000$ visitors per day, and have adopted large-scale infrastructure approaches which successfully minimise impacts and maintain conservation values, as confirmed by on-site audits. Key conservation concerns include off-park air and water pollution sources in some regions, and sale of items including threatened species, in $7 \%$ of parks.

\section{Introduction}

Management of the natural environment in protected areas (PAs), and of visitors who create environmental impacts in those areas, are critical components of conservation worldwide. Protected areas are key to conservation, and except for the highest-tier IUCN category-I PAs, most PAs in most countries are open for recreational visitation (Lockwood et al., 2012). Many IUCN category-II national parks, as well as providing critical habitat for threatened species and ecosystems, are also popular tourism destinations, and PA management agencies 
are required to balance the competing and often conflicting demands of conservation management and recreation management (Buckley et al., 2003; Bushell and Eagles, 2007; Buckley 2009a,b, 2010, 2011; Frost and Hall, 2009; Leung et al., 2015; Poudyal et al., 2013; Zhang et al., 2014). Management includes infrastructure, development control, impacts, wastes, education and monitoring. Visitors include independent travellers, tour groups and tourism operators. Protected areas include a range of different public and private land tenures, recognised either for natural or cultural heritage or both. Parks, tourism and management all have cultural contexts which may differ between and within nations. In particular, research on environmental and visitor management for protected areas within China is limited relative to that in Western nations. Here we address this gap.

China is the world's most populous nation, and many of its citizens now enjoy the wealth and freedom to travel extensively. By far the majority of this travel is domestic, dwarfing either inbound or outbound travel. During 2012, there were 130 million inbound visitors to China, 80 million outbound, and 2900 million domestic tourists (CNTA, 2013). Destinations include a wide range of natural, adventure and cultural attractions (Quan et al., 2009), with some individual parks attracting several million visitors annually. China is a highly biodiverse nation, with a wide range of ecosystems and numerous endemic and threatened species. There are at least 7 different types of protected areas in China, managed by different government agencies. The principal types are: Nature Reserves, Forest Parks, Geoparks, Wetland Parks, Scenic Areas, Water Parks, and Cultural Parks. Each of these types may be managed at three different levels, namely national, provincial or local. Irrespective of formal designation, each contributes to both conservation and recreation. There are $~ 8000$ protected areas in total nationwide, with $\sim 2500$ designated at national level and the others at provincial or local levels.

Nature-based tourism in China, including ecotourism and tourism to protected areas, has been examined from a range of perspectives in both Chinese- and English-language academic literatures. Topics include: concepts and definitions (Zhong and Xiao, 2000; Zhao, 2002; Buckley et al., 2008; Wang et al., 2012; Yang et al., 2000); ethics (Xu, 2003); geography (Yang and Yin, 2002); evaluation (Xu and Yang, 2005); awareness (Cheng, 2005); economics (He et al., 2008; Yang, 2012) case studies (Yang et al., 2000; Hang et al., 2011); conflicts (Wang et al., 2012; Zhang et al., 2014); and community interest and outcomes (Liu et al., 2012; Zhang and Lei, 2012). Overall, however, only 3.7\% of tourism research in China 
is on ecotourism, including tourism in parks (Bao et al., 2014). The broadest previous study is that by Quan et al. (2009). Here, therefore, we assemble and analyse a large-scale data set for Chinese protected areas, as a basis for international comparisons and to identify priorities for future research in China.

\section{Methods}

We analyse patterns and practices for management of visitors and environment at over one thousand individual parks throughout China. Using formal written multiple-choice survey questionnaires, we compiled data from park managers for $>160$ parameters related to tourism infrastructure, visitor management, community involvement, environmental management and environmental impacts. We selected 1200 individual conservation reserves throughout China, in all categories from scenic and cultural to large-scale forest conservation reserves, covering the full national range in geographic distribution, ecosystems, and level of government designation (Fig. 1). For each local government area in each Province, we first selected the principal park or parks designated at national level: 659 in all. We then added further parks at national, provincial or local level in each Province, choosing those which are largest, most pristine, or otherwise make the most significant contributions to conservation. Our selection thus covered all biomes and geographic regions, and all reserve categories and designation levels, using a multi-criterion selection process intended to include a nationally representative set of reserves most significant for conservation in China.

For almost all of these, at least one of the authors visited each park, delivered the survey questionnaires in person, and examined management practices on the ground. For a few inaccessible parks, we sent surveys by mail. For the more heavily visited parks, several of the authors visited either jointly or independently. A total of 1110 questionnaires (92.5\%) were completed in full. In each case, the respondents are the senior managers of the individual parks concerned. The survey was identified and presented as a research project, not a management exercise, and respondents were anonymous and able to express their views freely and without perceived-desirability bias. Survey questions were framed to allow categorical or ordinal responses, with two to six ranks. This yielded a very large and dense dataset with over 175,000 data cells. This appears to be the largest dataset on protected-area tourism yet compiled and analysed worldwide. 
Questions on tourism infrastructure examined: regional planning and park zoning; modes of transportation; and construction standards, level, locations and design of tourist accommodation, catering and facilities. Visitor management questions included: types of tourism development; ecotourism planning and regulation; scale and impacts of built infrastructure; and visitor quotas. Community involvement questions considered: effects on local income; community attitudes; opportunities for employment, training, sponsorships and souvenir sales; entrepreneurial involvement in ecotourism enterprises; and participation in ecotourism planning.

Environmental management questions covered: environmental standards in design, construction and operation of roads, tracks, toilets, etc.; biodegradable cleaners; sewage and solid waste treatment; air and water quality; water conservation measures; energy sources and energy efficiency; environmental impact assessment for construction; ecological monitoring and contingency plans; loss of native vegetation; soil degradation and water pollution; exploitation of threatened species; proportions of budgets allocated to conservation; impacts from quarrying, logging, poaching, plant harvesting, livestock grazing, firewood collection, fires, invasive species, and tourists feeding wildlife; impacts on water quality, e.g. from waste discharge, motorboats, and dams and barrages; visitor centres, museums, exhibitions, natural history signs, and environmental interpretation plans; the accuracy of interpretive materials; customisation to local ecology and culture; range of interpretive mechanisms and media; and guide skills and training.

There is a degree of innate heterogeneity in both the cases and the parameters. Apart from differences in size, age, budget and geographic region, the parks are of different types, held under different land tenure and established by different levels of government, and managed for different purposes. In addition, the cases are not distributed evenly between these types: nature reserves, forest parks and scenic areas are 4-15 times more numerous than geoparks, wetlands and waterparks. The parks are not evenly distributed geographically. There are many more smaller, lower-level parks in the south and east, and fewer, larger, higher-level parks in the northwest (Fig. 1). This reflects China's terrain, climate, and geopolitical and land-use history, notably the distinction between arable and pastoral agriculture.

Similarly, the parameters are not all of equivalent type, but fall into distinct groups as outlined in the preceding paragraphs. Analytical approaches such as ordination or clustering, 
which treat every case and characteristic equally, are therefore unlikely to yield reliable results for this data matrix. Since this was the first study of this type and scale in China, or indeed worldwide, there was no prior information for patterns in any of the parameters examined. We did not know in advance, for example, if the different types of protected area are very similar or very different; or which parameters may or may not be associated.

We therefore used two different parallel analytical approaches. In the first, we tested for patterns in each parameter independently, in relation to park type, level, region, age, budget and visitation. Since this involved a total of over 600 individual chi-square tests carried out $a$ posteriori, we used a conservative Bonferroni correction to reset significance probability to 0.0001 for individual tests. Since $n>1000$, a number of significant patterns emerge even at this level.

In the second approach, we amalgamated responses across individual questions to construct numerical indices for visitor management and environmental management respectively, and examined patterns in each index in relation to type, level, region, age, budget and visitation. As with all such indices, there are multiple possible algorithms for selecting, weighing and aggregating parameters. Our approach is as follows. We first scaled the responses to each question on $[0,1]$ so that each question received equal weighting. That is, for dichotomous questions the responses were coded as 0 or 1 ; whereas for a question with n possible responses ranked in order, the responses were coded as $0,1 /(n-1), 2 /(n-1), \ldots(n-2) /(n-1)$, 1. Within each index, the responses were then summed, and divided by the total number of parameters included, so that each aggregate index ranged from 0 to 1.

We calculated such indices at two levels of aggregation. At a lower level, we calculated five separate indices, for environmental conservation and quality, environmental infrastructure and technology, environmental management, environmental interpretation, and community involvement respectively. At the higher level, we calculated an overall environmental management index and a corresponding visitor management index. These combine measures of status or quality with measures of activity or performance, following practices in environmental and management certification. Effectively, therefore, they can be viewed principally as measures of management effort. These index approaches complement the analyses of individual parameters. 


\section{Results}

\subsection{Approach, presentation and patterns}

Each of the approaches taken here yields voluminous results. Here, therefore, we first present the most robust and large-scale patterns, those which are of particular relevance to managing China's parks for tourism, and managing tourism in China’s parks. Every individual pattern reported below is statistically significant at $p<0.0001$. That is, for every statement which is phrased in comparative terminology such as "larger", "higher", or "especially those..”, $p<$ 0.0001. That is, for each such comparative statement, there is the implied sentence, "This pattern is statistically significant at $p<0.0001$ ”. Geographic patterns are presented in seven regions: the northwest with 2 provinces, north (5), northeast (2), east (7), centre (3), south (3) and southwest (5). Patterns between types, levels, areas, budget brackets and visitation ranges are specified in the text. Frequencies within each category of each of these parameters are listed where the differences are sufficient to be relevant for conservation ecology or management.

The results as presented below thus involve a high degree of data compression. We report $>70$ individual patterns significant at $p<0.0001$, from a dataset of 1110 parks, 160 parameters, 177,000 data cells, and 600 chi-square tests. We then report higher-order associations between these individual parameters, effectively a meta-analysis of our own individual-parameter results. We also provide a parallel approach to this meta-analysis, through the use of multi-parameter aggregate indices. Our overall presentation focusses firstly on higher-order nationwide patterns, and secondly on individual patterns of particular significance for ecology and management. For conciseness and comprehensibility, we do not list full numerical results or context in the text, and nor do we test any specific a priori hypotheses regarding associations between parameters. We provide our full data set as Supplementary Online Materials, and we welcome further analyses, including the use of our data to test a priori hypotheses. For such tests, the Bonferroni correction used here need not be applied. This increases the number of statistically significant associations markedly.

\subsection{Reserves, revenues, visitors and activities}

Overall, $41 \%$ of the responses were from protected areas designated principally for conservation, namely nature reserves, forest parks, geoparks and wetland reserves. Somewhat fewer (37\%) were from scenic reserves; and the remainder from other tenures. One fifth of 
these protected areas were opened to visitors in the 1980s or earlier; 31\% during the 1990s; and 42\% since 2000. A small proportion, 7\% nationwide, have not yet been opened officially.

Just over a quarter of these protected areas nationwide have annual revenues of over five million yuan (USD 0.8 million). A little over one third (36\%) receive between 0-5 and 5.0 million yuan annually. The remainder (38\%) operate on less than 500,000 yuan per year, with $11 \%$ operating on less than 50,000 yuan. Scenic areas, and reserves managed at national scale, have higher revenues on average. Proportionally more nature reserves have low income, $<0.1$ million yuan annually.

Entry fees are charged at 73\% of protected areas nationally, especially for: forest parks, geoparks and scenic areas; the central, southern and eastern regions; and especially for those which were established earlier, have the highest budgets and visitation, and are operated by national agencies. Two-thirds of parks nationwide gain income from sales of food and accommodation; 41\% from souvenirs; and 74\% from local cultural goods. These sources of income are more frequent in parks with higher total revenue. Photographs and multimedia products are sold in 32\% and 25\% respectively, especially in nature reserves, forest parks and scenic areas.

At national scale, over a quarter of these reserves receive $>500,000$ visitors annually, and $44 \%$ receive $>100,000$. Heavily-visited parks are more frequent in the southern region, and for scenic areas. Provincial reserves, nature reserves and wetland parks, and those in the eastern and north-eastern regions, have proportionately lower visitation rates. All of these protected areas receive visitors from every stratum of modern Chinese society, specifically including farmers, soldiers, teachers, students, civil servants, business owners, company staff, factory workers, unemployed and retired people. The higher-revenue and more heavily visited parks receive more visitors who are retired or in senior management positions. These parks also receive higher proportions of visitors from other countries and distant parts of China, whereas the less-visited parks with lower revenues receive more visitors from local cities and provinces and from neighbouring provinces. Nationally, only $11 \%$ of protected areas receive international visitors, and two thirds of parks report that most of their visitors are from within the same province. Visitors from Taiwan, Hong Kong and Macau were treated as international. In line with the high proportion of domestic visitors, $73 \%$ of parks 
report that most of their visitors make their own travel arrangements, and stay only for a single day.

Most visitors to Chinese protected areas travel on foot (85\%), by car (60\%), or by bicycle (34\%). Travel by boat is also quite commonplace, available at $21 \%$ of protected areas nationwide. One in 10 protected areas nationwide operates a cableway or cablecar, and the proportion is higher (18\%) in the higher-budget and more heavily-visited parks, as compared to $5-6 \%$ in the less-visited areas. These proportions are very high on a world scale. At a national scale, $92 \%$ of protected areas have emergency plans; $71 \%$ have a defined emergency evacuation route; and 86\% have a designated safety supervisor and fire management plans. These proportions are significantly higher in the richer and more heavily visited parks, and slightly higher for scenic areas and forest parks. Almost all protected areas, 95\% nationwide, offer general sightseeing opportunities, and smaller proportions offer various more specialised activities. Birdwatching is available in $22 \%$, especially in nature reserves, water and wetland parks (32-50\%). Adventure tourism is offered in 27\%, especially in scenic areas, forest parks and geoparks (30-39\%), and especially in the central and south-western regions. Rural tourism with local cultural components is available in 53\%, especially in the central, east and south-western regions.

\subsection{Management, culture and communities}

Regulations for management of individual tourists are in place at $87 \%$ of parks nationwide; and regulations for management of ecotourism enterprises at $74 \%$. Both of these are more frequent at the older, higher-revenue and more heavily-visited parks. For almost all the parks studied (98\%), tourism marketing materials are considered by park managers to be accurate, in these sense of not misleading. Nationally, $84 \%$ of parks have taken deliberate measures to protect local cultural sites, and 64\% to protect modern minority cultures. Of course, these considerations only apply for those reserves where such sites and cultures exist.

Management agencies at every protected area nationwide report that local communities are in favour of tourism, and over $90 \%$ report at least a small increase in local income as a result of park-based tourism. The proportion is slightly lower for the most recent parks, and for those with lower visitation and lower budgets. Local communities participate directly in tourism at $84 \%$ of parks, especially in those with higher budgets and visitation. At $30 \%$ of parks nationwide, local residents run family hotels. The proportions are higher for national-level 
parks; those with higher budgets and visitation; and parks in the east and north-eastern regions. Local residents provide various forms of transport for hire at 34\% of parks; sell food at $25 \%$; and sell handicrafts at $11 \%$, especially in the older, lower-budget, lower-visitation and provincial level parks. At 10\% of parks, particularly those with lower budgets and visitation, local residents own and operate their own tour companies. All these figures are based on reports from parks agencies, not from local communities directly.

\subsection{Environmental impacts, management and interpretation}

Nationwide, 74\% of parks meet Level 1 of the Chinese national air quality standard GB30951996; 25\% comply with Level 2, and 1\% are at the lowest Level 3. This standard sets annual, 24-h and 1-h maximum mean concentrations for fine airborne particulates, lead, sulphur dioxide, carbon monoxide and nitrogen oxides. It is thus essentially a measure of urban pollution. Level 1 represents the highest air quality, with annual-mean thresholds of $0.02 \mathrm{mg}$ $\mathrm{m}^{-3}$ for $\mathrm{SO}_{2}$ and $0.05 \mathrm{mg} \mathrm{m}^{-3}$ for $\mathrm{NO}_{\mathrm{x}}$. Thresholds for $24-\mathrm{h}$ and 1-h time periods are twice and 3-7 times higher respectively. Level 2 standards are the same for $\mathrm{NO}_{\mathrm{x}}$, but are three times more lax for $\mathrm{SO}_{2}$. Level 3 standards are twice as lax as Level 1 for $\mathrm{NO}_{\mathrm{x}}$, and five times as lax for $\mathrm{SO}_{2}$. The proportions which comply with the Level 1 standard are higher for the richer and more heavily visited parks. There are no significant differences (at $p<0.0001$ ) between types and regions. As noted earlier, different regions have different total numbers of parks and different relative numbers of different types, and this heterogeneity reduces statistical discriminating power between regions.

Similarly, 59\% of parks nationwide comply with Level 1 of the national water quality standard GB3838-2002, with 31\% meeting the Level 2 standard and 10\% complying with Level 3. There are 5 Levels in all. This standard covers 24 different physical, chemical and microbiological parameters including oxygen demand, nutrients, heavy metals, industrial organic pollutants, and faecal coliform bacteria. There are no statistically significant differences (at $p<0.0001$ ) between regions, types or levels, or between parks with different age, budget or visitation rate. The uneven geographical distribution of different park types, however, (Fig. 1) reduces statistical discriminating power.

A variety of environmental impacts are reported. Waste management problems are reported at $57 \%$ of parks; water pollution at $23 \%$, especially in the densely populated eastern regions; air pollution at $8 \%$, noise at $11 \%$, damage to natural objects at $25 \%$, intrusive man-made 
features at $14 \%$, and cultural impacts at $6 \%$. There are no significant patterns for any of these parameters in relation to region, type, level, age, income or visitation. Most parks (83\%) treat at least $50 \%$ of their sewage, but few treat $100 \%$. Solid waste treatment is considered good at $58 \%$ of parks, but average to poor for the remainder.

In $70 \%$ of parks nationwide, at least $50 \%$ of toilets are of various low-impact types, principally composting toilets. Effective water-saving measures are in place in $60 \%$ of parks; locally-sourced low-impact building materials are used in 42\%; and biodegradable cleaners in $64 \%$. All of these measures are more commonplace in the older, higher budget and more heavily visited parks. Renewable energy sources are widely used, with 82\% of parks nationwide gaining at least half of their energy supplies from sources classified as clean energy. This, however, includes hydroelectric power, which has high impacts on riverine ecosystems. Buildings have been designed to use natural light in $64 \%$ of parks, and $19 \%$ have motion-detecting light switches. The original native vegetation of most parks is still in good condition, with only $4 \%$ reporting deterioration. Similarly, only $2 \%$ report significant soil and water loss. Only 36\% of parks nationwide, however, have well-established environmental monitoring programmes for these parameters. For the remainder, these reports are based solely on expert opinions of the park managers.

Illegal tree cutting is reported from 7\% of protected areas nationwide; wildlife poaching in $5 \%$; collection of herbs in 11\%; illegal grazing in 12\%; and damage to native trees in $15 \%$. The introduction of exotic species, and feeding of wildlife by tourists, are each noted as problematic in 3\% of parks. In addition, $7 \%$ of parks permit the sale of goods made from endangered species. The particular items sold were not specified, so it is possible, for example, that they are sold as ingredients in traditional Chinese medicines. It is also not clear whether the particular endangered species involved are from the parks where they are sold, or elsewhere in China, or indeed from other countries. Oil leaks from boats, and modifications to natural water flows, are each reported from $6 \%$ of parks nationwide, and $15 \%$ have observed dumping of garbage and wastewater directly into waterways.

Organised forms of environmental interpretation are widespread. There are planned and designated travel routes or circuits in $84 \%$ of protected areas nationwide, though less frequently in less-visited parks. At national scale, 52\% have museums or exhibition halls, 74\% have interpretive signs, $77 \%$ of parks have visitor centres, $83 \%$ provide printed 
information, and 85\% offer guiding services. Most of these opportunities are more frequent in the older, higher-budget and more heavily visited parks. Smaller proportions of parks offer expert lectures, specialised readings, and pre-planned educational activities. A visitor complaints or feedback service is available at $89 \%$ of parks nationally, though the proportion is lower in less heavily visited parks. Trained guides are available at 56\% of parks, particularly those with higher budgets and visitation rates. Untrained guides are available at $34 \%$ of parks, and $11 \%$ have no guides.

\subsection{Synthesis across individual parameters}

Examining patterns in each parameter independently, as above, yields three major conclusions. First, even with the very conservative and stringent Bonferroni correction applied, there are many parameters which do indeed show patterns significant at $p<0.0001$, as summarised above. That is, each of the patterns outlined here is very robust. Many other parameters, however, do not demonstrate statistically significant differences between parks of different type, level, region, age, revenue or visitation. Individual parks may differ, but not systematically. Since the parameters are categorical, and many are dichotomous, the degree of discrimination between individual parks is relatively coarse. For those parameters, only nationwide percentages across all parks are presented, as above. In addition, since the parameters are categorical, we cannot specify mean differences in specific parameters between different types of park, but only differences in frequencies of different categories, as above.

Secondly, many of the individual parameters, even considered independently as above rather than jointly, nonetheless demonstrate similar patterns. The principal such pattern is a difference between those parks with higher revenue and visitation, which in many cases are also longest-established; and those which have lower revenue and visitation, which in many cases are more recently established.

Thirdly, a number of parameters do show significant patterns related to geographic region, but different parameters show different patterns. We might expect to see consistent differences between parks in the less densely-inhabited regions of the north and west, and the more-densely inhabited regions of the south and east. In practice, this pattern only appears for a small number of individual parameters, and some parameters show completely different geographic patterns. This, however, applies using an a posteriori test at $p<0.0001$, applied 
to each parameter independently. We did not test for any particular geographic patterns $a$ priori. In addition, in these single-parameter analyses we did not test statistically for associations in geographic patterns between different parameters. Regional differences may also be masked by uneven geographic patterns in park distribution (Fig. 1).

\subsection{Aggregate indices}

The overall index of environmental management, and the overall index of visitor management, are correlated significantly (p_0.001) but loosely $(\mathrm{R} 2=0.22)$ across all 1100 parks. Both the environmental management and visitor management indices are correlated significantly with park visitation and income. As shown by patterns in individual parameters reported in the preceding sections, the icon parks necessarily devote more effort to management, and have greater resources to do so. The environmental management index is $12 \%$ higher for parks receiving $>100,000$ visitors annually than for parks receiving $<10,000$, and $10 \%$ higher for parks with annual income $>5,000,000$ yuan than for those with annual income 100,000 yuan. The mean visitor management index, however, is 37-38\% higher for parks with highest visitation (0.68 cf 0.49 ) and largest annual income (0.70 cf 0.51$)$. That is, as might be expected, the effort invested in visitor management is more than three times as sensitive to visitor numbers and budget than the effort invested in environmental management.

For the environmental management index, there are no significant differences between the different types of park. The visitor management index, however, is significantly $(p<0.001)$ and substantially (14\%) higher for scenic areas and geoparks than for nature reserves, water parks and wetland parks, with forest and cultural parks intermediate. Both indices are lower, on average, for parks managed at provincial government level than at either national or local levels. The differences are around $4 \%$ for the environmental management index and $12 \%$ for the visitor management index. Both the environmental and visitor management index are lowest for the southwest region and highest for the south and east regions, but the difference is $<10 \%$.

Of the five subsidiary indices, those related to environmental conservation and quality, environmental infrastructure and technology, environmental management, and environmental interpretation were all correlated significantly with income and visitation. The five indices are all correlated with each other, with Spearman's rho ranging from 0.32 to 0.58 and $p<$ 
0.01 in each case. The four environmental subindices are all lower for parks which started operations in the 1980s and 1990s than those which started either earlier or later, but the community involvement index is highest for those which opened in the 1990s and 2000s, and lower for older and younger categories. Overall, these five subindices confirm patterns reported above for the higher-level aggregate indices and for individual parameters.

\section{Conclusions}

The results reported above show numerous significant patterns $(p<0.0001)$ for individual environmental and visitor management parameters. Taken together, these demonstrate a large-scale pattern between older parks with more visitors and funds, and younger parks with less. This pattern was not previously known or apparent, and nor is it obvious or expected. It cuts across the broad geographical division between large, recently-established and lessvisited parks in the northwest and northeast, and smaller, longer-established and heavilyvisited parks in the south and centre. The well-known iconic parks have adopted a broader range of environmental and visitor management measures. They have greater need for such measures, since they have more visitors; and they have greater capability, since they have larger budgets. It is notable that budget and visitation rates are much more powerful predictors of management measures than either type, level or region. That is, the practicalities associated with high levels of visitation override differences between land tenure type, management agency, and geographic location.

If we compare the overall nationwide pattern in China's parks against other countries, several factors stand out. First, a relatively high proportion of parks in China operate intensive infrastructure such as cableways. Examples include the $7.5 \mathrm{~km}$ cableway at Tianmenshan, and the $330 \mathrm{~m}$ Bailong vertical elevator at Wulingyuan. This reflects China's position as the world's most populous country, which leads to particularly high visitation rates for betterknown parks. The approaches to visitor management and infrastructure in China's very heavily-visited icon parks can provide expertise valuable to many other nations also experiencing high tourism to particular protected areas. These approaches therefore merit more detailed research in future.

Second, these results show that a relatively high proportion of parks in China raise at least part of their revenue through sales of food, souvenirs and so on, in addition to entry fees. We did not ask whether these sales are carried out directly by the parks agency, or whether they 
are licensed to private enterprises or concessionaires operating within the parks. Nor did we examine the proportions of budget raised through these approaches. The degree to which China's parks have or may become financially self-sustaining through tourism is of immediate relevance to other highly populous nations such as India and Brazil. This issue thus deserves greater attention. Many countries raise significant proportions of parks agency budgets from visitor fees, typically around $10 \%$ for developed nations but over $50 \%$ for some developing nations (Buckley et al., 2012). Corresponding data are not yet available for China, but would be well worth compiling.

And third, even though visitation rates are high, visitor impacts are generally well managed. As reported by the park managers surveyed here, the principal environmental threats are due to encroachment and illegal uses such as poaching, livestock grazing, tree cutting and herb collecting. In particular, managers at $7 \%$ of parks report the sale of items made from endangered species. This is always of conservation concern, but especially when it occurs within a protected area. The species involved, volume of trade, and cultural context for this industry deserve close attention in future research. Such data would be important for conservation of individual threatened species within China and perhaps also internationally.

From a conservation perspective, therefore, these results provide a broad but nonetheless relatively detailed and comprehensive analysis of environmental and visitor management in the Chinese protected area system. They show that despite a range of different land tenure types, management practices are influenced more by the age, size, visitation and budget of the area concerned than by the tenure type or management agency. This contrasts with most other nations, where land tenure type is an overriding determinant of management practices. These results also suggest a number of topics where Chinese experience would be of particular value in other countries, perhaps most notably the design of large-scale infrastructure to manage very large visitor numbers.

These results also indicate a number of topics important to improve management of parks in China. These include: better information on budget breakdowns, especially with regard to income from tourism; more widespread environmental monitoring; and particular attention to the sale of artefacts including threatened species. It would also be valuable to learn more about the factors influencing visitor behaviour, including choice of park and activity, and success of interpretation and impact-management measures. Such studies have been 
undertaken at local scale for individual parks in China (e.g., Li et al., 2012), but not as yet at a broad national scale.

\section{References}

Bao, J., Chen, G., Ma, L., 2014. Tourism research in China: insights from insiders. Ann. Tourism 45, 167-181.

Buckley, R.C., 2009a. Parks and tourism. PLoS Biol. 7 (6), e1000143.

Buckley, R.C., 2009b. Ecotourism: Principles and Practices. CABI, Wallingford.

Buckley, R.C., 2010. Conservation Tourism. CABI, Wallingford.

Buckley, R.C., 2011. Tourism and environment. Ann. Rev. Environ. Res. 36, 397-416.

Buckley, R.C., Pickering, C.M., Weaver, D. (Eds.), 2003. Nature-Based Tourism, Environment and Land Management. Wallingford, CABI.

Buckley, R., Zhong, L.-S., Cater, C., Chen, T., 2008. Shengtai luyou: cross-cultural comparison in ecotourism. Ann. Tourism Res. 35 (4), 945-968.

Buckley, R.C., Castley, J.G., Pegas, F., Mossaz, A.C., Steven, R., 2012. A population accounting approach to assess tourism contributions to conservation of IUCN-redlisted mammals. PLoS ONE 7 (9), e44134.

Bushell, R., Eagles, P.F.J., 2007. Tourism and Protected Areas: Benefits Beyond Boundaries. CAB International, Wallingford, United Kingdom.

Cheng, Z.K., 2005. Awareness of the ecotourism concept. J. Shanxi Univ. 28 (1), 24-26 (in Chinese).

CNTA. 2013. Tourism Statistics. China National Tourism Administration, Beijing. www.cnta.gov.cn (in Chinese).

Frost, W., Hall, C.M. (Eds.), 2009. Tourism and National Parks. Routledge, Oxford.

Hang, T.-C., Gao, J.-Q., Guo, J.X., Peng, Y., Hu, S.-H., 2011. Research on ecotourism. J. Tianjin Univ. 13 (6), 505-510 (In Chinese).

He, G., Chen, X., Liu, W., et al., 2008. Distribution of economic benefits from ecotourism: a case study of Wolong Nature Reserve for Giant Pandas in China. Environ. Manage. 42, 1017-1025.

Leung, Y.-F., Spenceley, A., Hvenegaard, G., Buckley, R. (Eds.), 2015. Tourism and Visitor Management in Protected Areas: Guidelines Towards Sustainability. IUCN, Gland.

Li, J., Yang, D., He, L., Tao, S., Zeng, L., Buckley, R., 2012. Psychological, physiological and behavioural responses of tourists to interactions with rhesus macaques at Zhangjiajie, 
China. J. Ecotourism 11, 202-206.

Liu, W., Vogt, C.A., Luo, J., He, G., Frank, K.A., Liu, J., 2012. Drivers and socioeconomic impacts of tourism participation in protected areas. PLoS ONE 7 (4), e35420.

Lockwood, M., Worboys, G., Kothari, A., 2012. Managing Protected Areas: A Global Guide. Earthscan, London.

Poudyal, N.C., Paudel, B., Tarrant, M.A., 2013. A time series analysis of the impact of recession on national park visitation in the United States. Tourism Manage. 35, 181-189.

Quan, J., Ouyang, Z.-y., Xu, W.-h., Miao, H., 2009. Management effectiveness of China nature reserves: status quo assessment and countermeasures. Chin. J. Appl. Ecol. 20 (7), 1739-1746.

Wang, G., Innes, J.I., Wu, S.W., et al., 2012. National park development in China: conservation or commercialization? Ambio 41, 247-261.

Xu, F., 2003. The ethical implications of ecotourism. Ideol. Front 29 (4), 73-75 (in Chinese).

Xu, F., Yang, D.-Y., 2005. Evaluation of wetland ecotourism based on hierarchical entropy analysis method. Econ. Geogr. 25 (5), 707-711.

Yang, Y., 2012. Agglomeration density and tourism development in China: an empirical research based on dynamic panel data model. Tourism Manage. 33, 1347-1359.

Yang, G.-F., Yin, Y.C., 2002. Outlook for GIS in ecotourism. J. Nat. 24 (4), 231-233 (in Chinese).

Yang, G.H. Zhong, L.S., Ming, Q.Z., 2000. Ecotourism, second ed. Higher Education Press, Beijing (in Chinese).

Zhang, H., Lei, S.L., 2012. A structural model of residents' intention to participate in ecotourism: the case of a wetland community. Tourism Manage. 33, 916-925.

Zhang, C., Fyall, A., Zheng, Y., et al., 2014. Heritage and tourism conflict within World Heritage sites in China: a longitudinal study. Curr. Iss. Tour..

http://dx.doi.org/10.1080/13683500.2014.912204.

Zhao, H., 2002. Ecotourism: the only way to sustainable development of tourism in our country. Acad. Exch. 103 (4), 99-101 (in Chinese).

Zhong, L.-S., Xiao, D.-N., 2000. Ecotourism and its planning and management, a review. Acta Ecol. Sin. 20 (5), 841-848. 


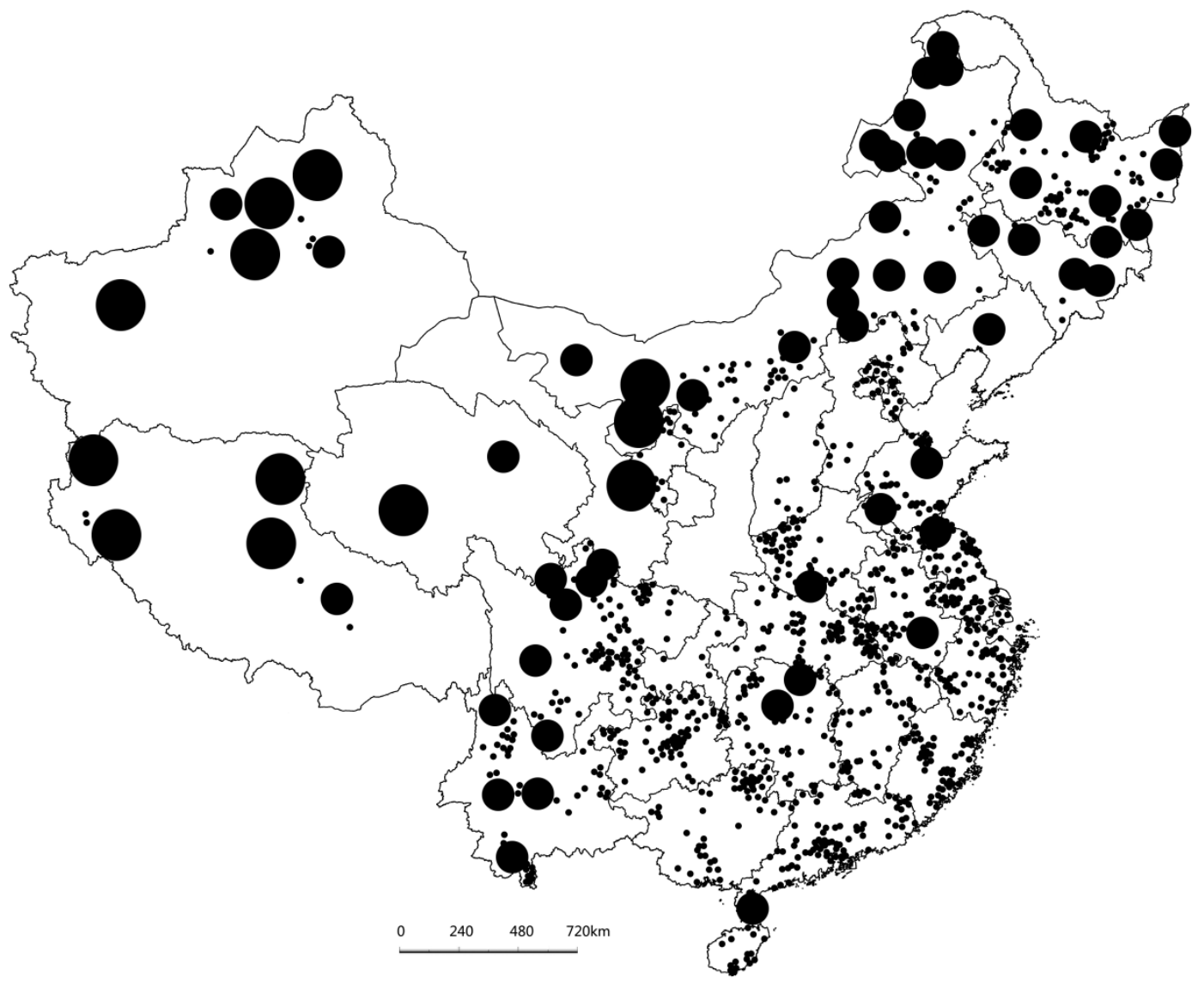

Fig 1. Map of mainland China showing individual parks studied, in three size classes: large solid circles, $>10,000 \mathrm{~km}^{2}$; medium solid circles, 1000-10,000 $\mathrm{km}^{2}$; small solid circles, $<1000$ $\mathrm{km}^{2}$. Lines show boundaries of Provinces. 